Engineering Sustainability

Volume 171 Issue ES1

Sustainability and resilience analyses in slope stabilisation

Das, Puppala, Bheemasetti, Walshire and

Corcoran

ice | proceedings
Proceedings of the Institution of Civil Engineers Engineering Sustainability 171 February 2018 Issue ES Pages 25-36 https://doi.org/10.1680/jensu.16.00054 Paper 1600054

Received 27/06/2016 Accepted 11/11/2016

Received 27/06/2016
Published online 16/12/2016

Keywords: dams/slopes - stabilisation/sustainability

\title{
Sustainability and resilience analyses in slope stabilisation
}

1 Jasaswee T. Das EIT

Doctoral student, Department of Civil Engineering, University of Texas at Arlington, Arlington, TX, USA

2 Anand J. Puppala PhD, PE

Professor, Department of Civil Engineering, University of Texas at Arlington, Arlington, TX, USA (corresponding author: anand@uta.edu)

3 Tejo V. Bheemasetti PhD

Research Associate, Department of Civil Engineering, University of Texas at Arlington, Arlington, TX, USA
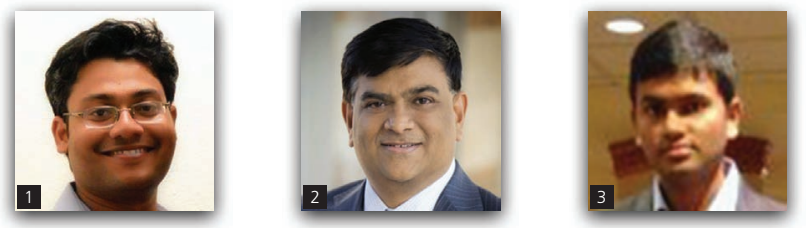

4 Lucas A. Walshire PE

Research Geotechnical Engineer, US Army Engineer Research and Development Center, Vicksburg, MS, USA

5 Maureen K. Corcoran PhD, RPG

Associate Technical Director, Water Resources Infrastructure, US Army Engineer Research and Development Center, Vicksburg, MS, USA

A number of models, metrics, benchmarks and charts have been developed to assess the sustainability of an engineered system. However, in the majority of these models, the concept of resilience is sequestered from sustainability, which generally focuses on socio-economic impacts and environmental stewardship. This paper attempts to present an approach that balances both sustainability and resilience aspects. To illustrate this, a surficial slope stabilisation research project in which several treatment methods were studied is used as a test platform. Both sustainability and resilience elements are quantified for each treatment method and are attached with appropriate weights based on their relative importance and at the discretion of the engineer. These weighted indicators are subjected to a multi-criteria analysis to designate a cumulative sustainability and resilience index ( $I_{\text {CSR }}$ ) that parametrises the degree of sustainability and resilience in the system. The treatment method with the least $I_{\mathrm{CSR}}$ is recommended for final field implementation.

\section{Notation}

$A_{\mathrm{P}} \quad$ acidification potential

$E_{\mathrm{E}} \quad$ embodied energy

$E_{\mathrm{P}} \quad$ eutrophication potential

$F_{\mathrm{S}} \quad$ factor of safety

$G_{\mathrm{WP}} \quad$ global warming potential

$I_{\mathrm{CSR}} \quad$ cumulative sustainability and resilience index

$I_{\text {Env }} \quad$ environmental impact index

$I_{\text {Rec }} \quad$ resource consumption index

$I_{\text {Res }} \quad$ resilience index

$I_{\text {SoEc }} \quad$ socio-economic impact index

$I_{\text {Sus }} \quad$ sustainability index

$P_{\mathrm{F}} \quad$ probability of failure

$W \quad$ attached weight

\section{Introduction and background}

Traditional civil engineering design and construction processes have focused on the safety and serviceability of infrastructure. In recent years, most engineered systems or infrastructure are typically designed to withstand external and internal disturbances without considerable loss of functionality over time while enhancing sustainability elements in every phase of the design. Civil infrastructure such as commercial and residential buildings, dams, roadway embankments, bridges and tunnels serve the economic interests of the community. They consume natural resources during construction and operation and generate emissions that affect the environment. The integrity and serviceability of the constructed system is tied to societal vulnerability, as in the case of a multipurpose dam project that involves the displacement of communities from downstream areas. Thus, the sustainability of an engineered system is interconnected with the global sustainability agenda, which has been stated as 'improving the quality of human life while living within the carrying capacity of the supporting ecosystems' (IUCN, UNEP and WWF, 1991). The World Summit (UN General Assembly, 2005) on Social Development identified economic development, social development and environmental protection as the three pillars of sustainability.

Geotechnical engineering is an inherent component of almost every constructed system or major infrastructure, and improving the sustainability of geotechnical processes is paramount to ensuring overall sustainable development (Basu et al., 2014; Jefferis, 2008; Long et al., 2006; Pender, 2011). Furthermore, as Pantelidou et al. (2012) noted, the scope of sustainability decreases as a project progresses from the planning to the implementation stage. Geotechnical engineering, being positioned at the incipient stages of 
a project, provides immense opportunities for sustainable development practices. The adoption of sustainable geotechnical alternatives at the initial stages can contribute towards the sustainability of the project at later stages (Basu et al., 2014).

Resilience-based designs are now being incorporated that will address the threats faced by infrastructure against sudden natural and man-made hazards. Bruneau et al. (2003) proposed four parameters ('the four Rs') as measures of infrastructure resilience: $(a)$ robustness, or the capacity to withstand a certain level of stress without functional damage; $(b)$ redundancy, dictated by the extent to which a component is substitutable in the event of damage; (c) resourcefulness, or the ability to identify disruptions and set up mechanisms to address the same; and $(d)$ rapidity, with which the external disturbances are addressed and losses contained. According to Bocchini et al. (2013), holistic consideration of both sustainability and resilience is indicative of the quality of an infrastructure element (Figure 1). They contended that sustainability and resilience are two complementary attributes of an infrastructure. While sustainability deals with the steady impacts on the environment, economy and society over the service life of an infrastructure, resilience chiefly addresses the sudden impact due to unanticipated failure. Measures or metrics of both sustainability and resilience and how they can be addressed together in a construction project (an engineered slope system in this case) are hence the major focus points of this study.

In advocating a rigid sustainable approach, prudence must be exercised such that the safety and reliability of the design is not compromised. This is particularly important for critical lifeline infrastructure such as dams and levees. As Abreu et al. (2008) observed, the risk and liability involved in geotechnical designs often take precedence over sustainability due to the high level of responsibility attributed to professional engineers to design a system that will serve safely for a given life period. In fact, from a geotechnical perspective, sustainability may be interpreted as a dynamic equilibrium between four Es - engineering design, economy, environment and equity, as noted by Basu et al. (2014).

The primary focus of this paper is to present a comprehensive framework that will evaluate both sustainability and resilience metrics in a given infrastructure project for various design

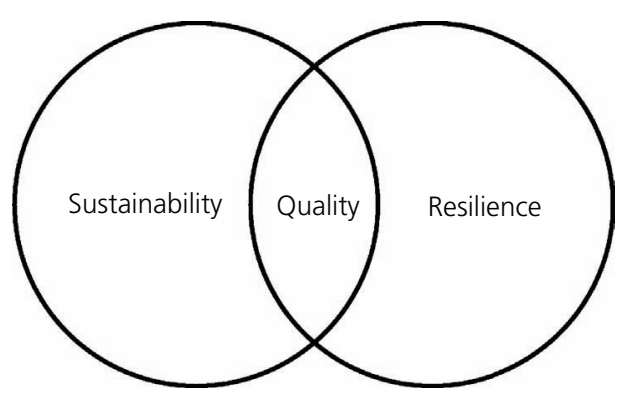

Figure 1. Quality of infrastructure requires both sustainability and resilience (Bocchini et al., 2013) alternatives. To demonstrate the framework and how it can be evaluated, a research study performed at the University of Texas at Arlington (UTA) has been used as an example case. In this research project, several treatment methods were employed to stabilise dam embankment slopes so that they do not undergo surficial failures. This case study is used to assess the sustainable metrics of treatments while evaluating the resilience of the same treatment methods in providing stable solutions during extreme natural events. The cause and mechanism of surficial failures occurring on the face of dam embankments, along with repair and stabilisation methods, are discussed in the following sections.

\section{Dam embankments}

\subsection{Surficial slope failures}

Surficial failures on slopes of earth dams are common in North Texas, particularly after heavy, sustained rainfall following a long dry spell (Puppala et al., 2013). These failures are shallow (infinite slope failure mode analysis is effective) and constrained to a depth of about 4 feet $(1.22 \mathrm{~m})$ below the surface (Evans, 1972). Figures 2 and 3 depict shallow failures on the slopes of dams in Texas. The predominant cause of such shallow failures is shrinkage-induced cracking in soils. During the dry season, the compacted clay slopes are subjected to high tensile stresses due to moisture loss and subsequent shrinkage, leading to the formation of desiccation cracks in the surficial layers. During the wet period, rainwater infiltrates the fissures, causing the surficial clay to swell and saturate, accompanied by a significant loss in shear strength. With sustained rainfall, seepage develops parallel to the surface (Day and Axten, 1989). The shear stresses mobilised within the soil mass continue to increase and ultimately exceed the saturated soil shear strength, causing failure of the slope.

Natural landslides and embankment slope failures disrupt transportation networks, and the repair costs can be exorbitant,

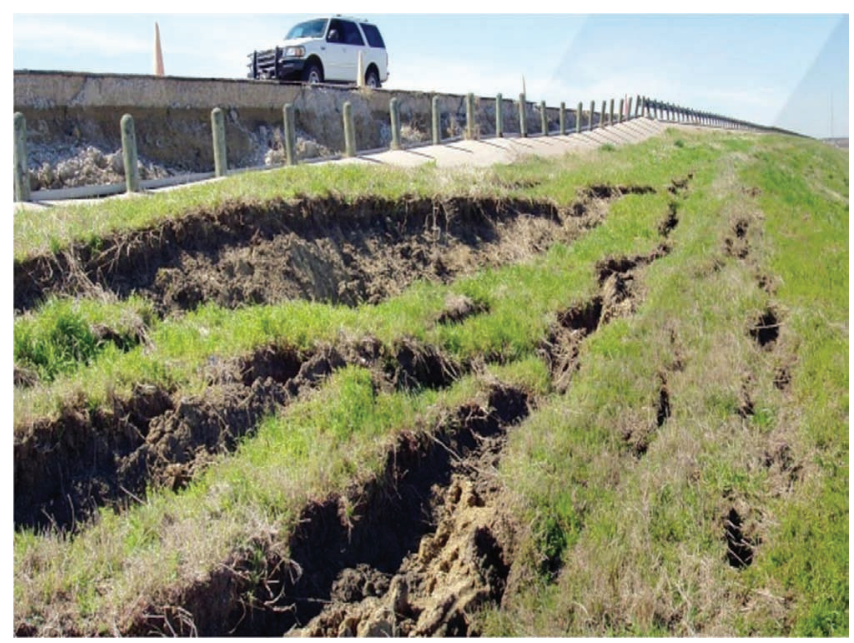

Figure 2. Surficial slope failure at Joe Pool dam (Courtesy: US Army Corps of Engineers (USACE), Fort Worth District) 
Sustainability and resilience analyses in

slope stabilisation

Das, Puppala, Bheemasetti, Walshire and Corcoran

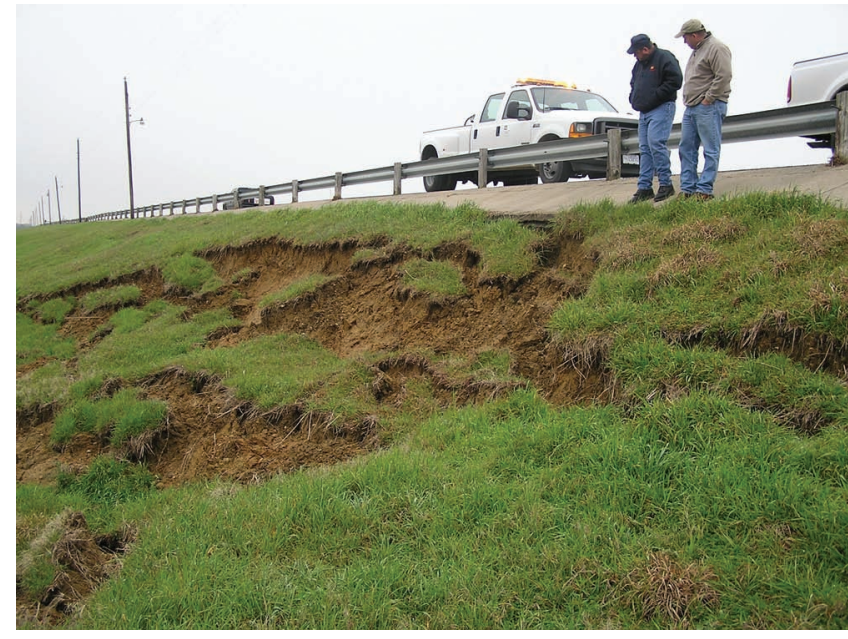

Figure 3. Surficial slope failure at Grapevine dam (Courtesy: USACE, Fort Worth District)

ranging from US\$10000 for temporary repairs to over US $\$ 100000$ for thorough repairs. Many dams are critical infrastructures, and substantial loss of their functional integrity due to surficial slope failures might be catastrophic in the long run. It is therefore important to address issues concerning surficial stability and come up with suitable ground improvement and/or other remediation measures to arrest these failures.

\subsection{Slope treatments}

Abramson et al. (2002) suggested various measures, such as excavation of weak strata, provision of adequate drainage, soil reinforcement, vegetation, placement of erosion control mats, grouting and lime injection, to improve the shear strength of embankment soil. Leong (2006, 'Greening geotechnical slope stabilization: a sustainable challenge in Asia', unpublished) and Wu et al. (2008) studied the applicability of soil bioengineering as a sustainable substitute for slope stabilisation. Vinod et al. (2010) recommended the use of lignosulfonate to promote surface vegetation and biodiversity. The National Cooperative Highway Research Program report Cost-effective and Sustainable Road Slope Stabilization and Erosion Control proposes erosion control techniques such as grass seeding and use of chemical stabilisers, biotechnical stabilisation and on-site soil reinforcement to inhibit surficial failures (NCHRP, 2012).

Early repair and restoration can be beneficial and cost-effective. A widely used repair method involves recompacting the failed soil mass and regradation of the slope. This solution is often temporary in nature, with surficial failures recurring after subsequent rainfall events. Conventional mitigation measures also employ expensive techniques such as mechanical stabilisation (soil nails, anchors, geosynthetics, recycled plastic pins). However, the aforementioned methods often involve practical difficulty of site access and working on the face of the slope (Day and Axten, 1989).
Ground improvement practices to stymie shallow failures have employed chemical admixtures such as lime and engineered geomaterials such as compost with reasonable success in the field. The selection of materials for surficial slope stabilisation is, generally, based on strength considerations and cost implications. A research study conducted at the UTA studied four different treatments in stabilising surficial slopes of a dam embankment (Dronamraju, 2008; Le, 2013; McCleskey, 2005; Saride et al., 2010). Extensive laboratory-to-field performance data are available which were used to assess the effectiveness of each treatment in stabilising surficial embankment soils. These results were used in the present analysis.

\section{Research study details}

A research study was undertaken at UTA, supported by the USACE Fort Worth District, to study the efficacy of several combinations of stabilising agents including lime, fibres and compost towards inhibiting surficial slope failures at Grapevine dam. The dam was constructed for flood control purposes and is located $32 \mathrm{~km}$ north-west of Dallas. Based on laboratory studies, four different combinations were considered: $20 \%$ compost, $8 \%$ lime, $4 \%$ lime with $0 \cdot 30 \%$ polypropylene (PP) fibres and $8 \%$ lime with $0 \cdot 15 \%$ PP fibres (Dronamraju, 2008; Le, 2013; McCleskey, 2005). Details of these stabilisers are given in the next section.

\subsection{Stabilisers used in the study}

\subsubsection{Lime}

Stabilisation of soils by using lime is one of the oldest methods of enhancing soil strength. The addition of lime leads to short-term and long-term reactions. The short-term reactions associated with this treatment method are cation exchange, agglomeration and flocculation. These processes increase the workability of soil, which results in soil modification. The long-term reactions include pozzolanic reactions and carbonation. Carbonation of lime is slow and leads to the formation of calcium carbonate. The pozzolanic reactions with clay minerals form cementitious products. This process results in soil stabilisation, which improves the strength of the soil and increases its resistance to volumetric changes (McCleskey, 2005).

\subsubsection{Biosolid compost}

Puppala et al. (2005) reported that hydrophilic characteristics and the presence of fibrous material in biosolid compost can reduce shrinkage and inhibit shoulder cracking of highway pavements. However, the treated soils have high swell potential due to the moisture affinity of the compost ingredients. Based on laboratory tests by McCleskey (2005), an optimum compost dosage of $20 \%$ was employed for ground improvement.

\subsubsection{Polypropylene fibres}

Polypropylene fibres are one of the most commonly used synthetic fibres for soil reinforcement. Previous studies by Puppala and Musenda (2000) showed that the addition of fibres to soil increases its resistance towards swelling and shrinkage besides improving the unconfined compressive strength characteristic. McCleskey 
Sustainability and resilience analyses in

slope stabilisation

Das, Puppala, Bheemasetti, Walshire and Corcoran
(2005) reported that the use of fibres increased the tensile strength of the soil, making it less susceptible to shrinkage cracking.

Laboratory studies were performed on soils stabilised with the treatments mentioned earlier and were subjected to swell, shrinkage and soil strength tests. Additionally, a field implementation programme was carried out by building test sections on Grapevine dam. The testing area was divided into five sections, including four treated sections, each with an additive above, and one control section, as illustrated in Figure 4. A schematic diagram of the slope is shown in Figure 5. The top soil was excavated to a depth of $23 \mathrm{~cm}$ and stockpiled to be placed back over the treated section for the purpose of vegetation growth. The core soil was mixed with admixtures in a soil processing area nearby to form a $46 \mathrm{~cm}$ thick treated section (Figure 6). The test sections with treated soil were properly compacted with sheep foot rollers. Standard quality control measures were adopted during the construction and mixing process. These test sections were instrumented with moisture probes, temperature sensors and inclinometers for monitoring lateral movements along the slope. The sustainability and resilience of each treatment method was evaluated based on certain quantifiable parameters for the stabilised slope system, as described in the next section.

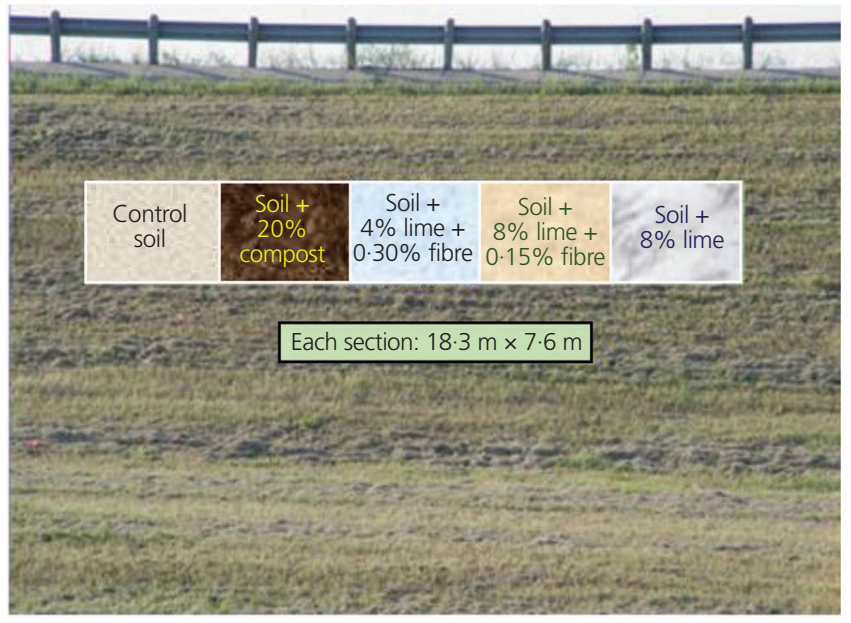

Figure 4. Layout of test sections

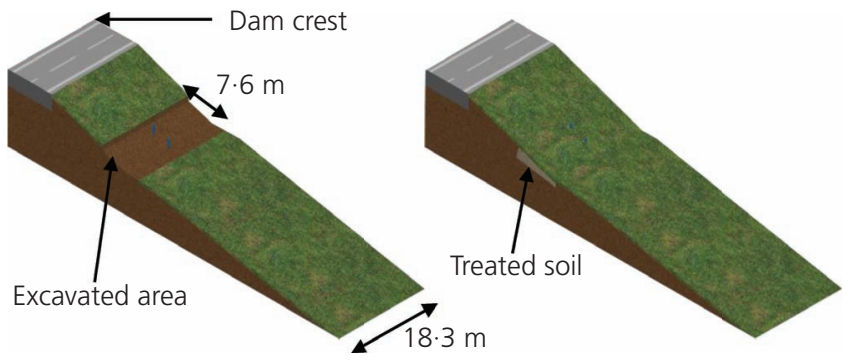

Figure 5. Schematic diagram of a section of slope

\section{Proposed sustainability and resilience framework}

As mentioned earlier, it is important to consider both resilience and sustainability aspects along with strength improvements in studying various treatment alternatives. Jimenez (2004) developed a sustainability geotechnical evaluation model (SGEM) for comparing the sustainability of conventional slope stabilisation measures, such as the cut-and-fill method, recycled plastic pins, soil nails, lime piles and vegetation, based on social, natural resources, environment and economic indicators. Holt et al. (2009) devised a colour-coded indicator system called GeoSpear, based on the Sustainable Project Appraisal Routine (Spear), to assess the sustainability of geotechnical projects.

The proposed framework was developed based on a multi-criteria evaluation of resource consumption, environmental impact and socio-economic impact, suggested by Misra (2010), and integrates measures of resilience into the assessment. Unlike SGEM or GeoSpear, the proposed model takes into account strength considerations and reliability. The ultimate aim was to effectuate the development of a comprehensive framework that conflates resilience with the sustainability agenda. One of the objectives of this framework development and assessment is to quantify resource use, gauge societal impact, examine environmental consequences and estimate the reliability of each ground improvement method in providing effective solution in mitigating slope failures. Accordingly, a life cycle assessment (LCA) is performed to quantify the environmental impact (environmental impact assessment (EIA)), while the estimation of embodied energy in the system constitutes the inventory analysis part of the LCA. Figure 7 demonstrates the different stages/steps of the proposed assessment framework.

The framework is based on a multi-factor evaluation that involves assigning weights to the impact categories based on their relative importance. The impact indicator is calculated by summing

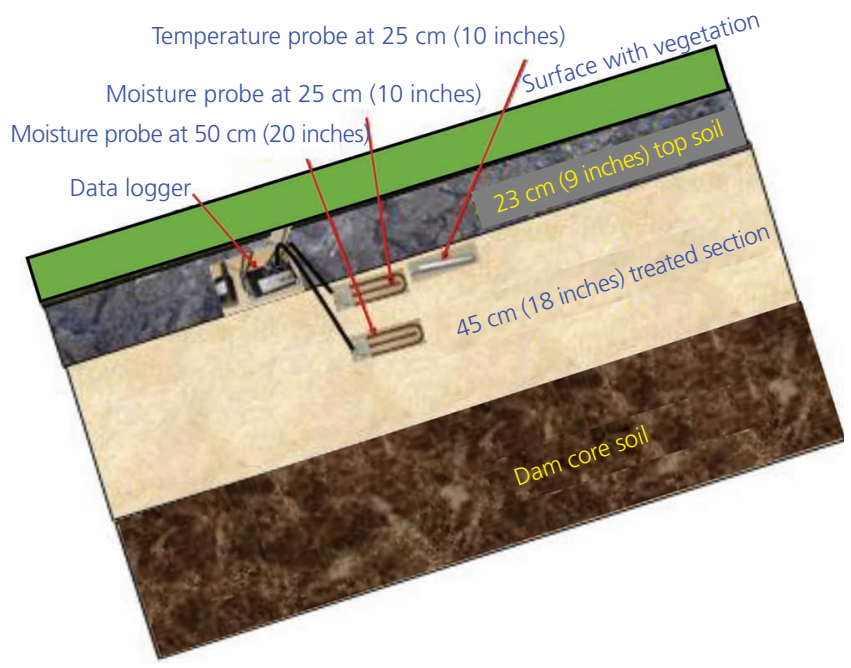

Figure 6. Cross-section details 


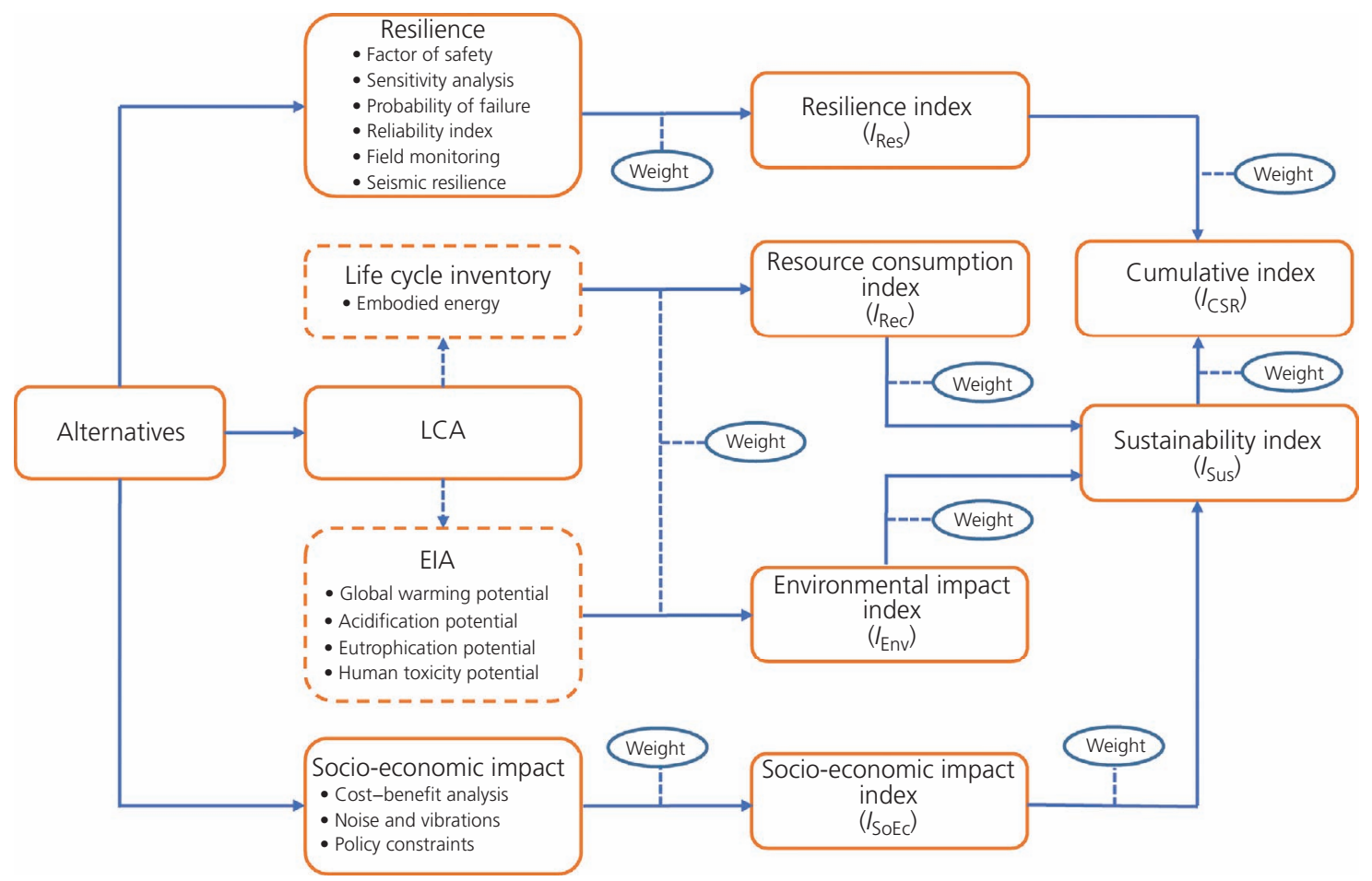

Figure 7. Proposed analysis framework

the product of the percentage contribution of each treatment method in a category and the corresponding weight. The cumulative sustainability and resilience index $\left(I_{\mathrm{CSR}}\right)$ is obtained by attaching proper weights to the sustainability and resilience indices. Proper discretion should be exercised while assigning weights to the impact categories. The sum of all the weights should be unity. The choice of weights ultimately depends on the user, as there is no consensus yet on the selection of weighting methods and values of the weights (Finnveden, 1999). A greater impact value implies a less sustainable or resilient alternative. It may be noted that the framework does not address the effectiveness of a treatment method. It facilitates the assessment of sustainability and resilience of each method while recommending the best alternative based on least $I_{\mathrm{CSR}}$.

In performing the combined sustainability and resilience analysis, certain assumptions were made. These include the average fuel consumption of the dump truck used in transporting soil from the borrow site to the test section and that of the truck used in transporting lime/fibres $(2 \cdot 3 \mathrm{~km} / \mathrm{l})$, the capacity of the dump truck used for transporting the soil from the borrow pit to the dam section $\left(8 \mathrm{~m}^{3}\right)$, the average distance travelled by the truck in transporting the soil from the borrow pit to the dam section (less than $1.6 \mathrm{~km}$ ), and the price of 1 litre of gasoline (US\$0.92). Cost data (per kilogram of stabiliser) were obtained from the manufacturers.

Based on the average section dimensions $(18.3 \mathrm{~m} \times 7.6 \mathrm{~m} \times 0.46 \mathrm{~m})$ and average compacted unit weight of on-site soil of $14.7 \mathrm{kN} / \mathrm{m}^{3}$, the mass and volume of the treated soil are approximately $96000 \mathrm{~kg}$ and $64 \mathrm{~m}^{3}$, respectively. The treatment dosages used were $20 \%$ compost, $4 \%$ lime $+0 \cdot 3 \%$ PP, $8 \%$ lime $+0 \cdot 15 \%$ PP and $8 \%$ lime. These values translate to $19200 \mathrm{~kg}$ of compost for section 2 , $3840 \mathrm{~kg}$ of lime $+303 \mathrm{~kg}$ of PP for section $3,7680 \mathrm{~kg}$ of lime + $152 \mathrm{~kg}$ of PP for section 4 and $7680 \mathrm{~kg}$ of lime for section 5.

\subsection{Resource consumption}

Resource consumption is determined through life cycle inventory analysis by way of energy (or mass) accounting methods. The analysis was performed based on the embodied energy of each treatment system (Chau et al., 2006; Misra, 2010; Storesund et al., 2008). Embodied energy $\left(E_{\mathrm{E}}\right)$ may be construed as the energy expended in construction and maintenance of the stabilised system, including the energy required for production, transportation, handling and disposal of the stabiliser. For the purpose of this study, it is assumed that the energy expended during construction is similar across all methods. Since each treatment method involves identical construction machinery and follows the same procedure - namely excavation of top soil and core soil, addition of stabiliser, mixing, placement of treated soil, watering and compaction - the aforementioned assumption is reasonable. However, the energy consumed during operation and maintenance is difficult to audit and has been kept outside the scope of this study. Soil and water are not considered as limited resources and hence are not included in the analysis.

Embodied energy values for lime and PP were obtained from the Inventory of Carbon and Energy (ICE) database prepared 
at the University of Bath (Hammond et al., 2011). The database adopts a 'cradle-to-gate' approach, considering a partial LCA from the extraction phase (cradle) to factory gate (prior to transportation to the consumer). It is worthy of mention that the compost used in this pilot study is primarily derived from biosolids. Due to the absence of a systematic LCA of the compost used, the embodied energy calculation for the material is based on the values reported by Aziz et al. (2015) for granular compost sourced from agro-industrial wastes and animal manures. The energy embodied in the transportation of materials is computed based on the assumptions made in the preceding section. The resource used by each admixture was quantified in megajoules per kilogram. The resource impact index $\left(I_{\mathrm{Rec}}\right)$ was calculated as

$$
\begin{aligned}
I_{\mathrm{Rec}}= & W_{1} \times\left(\% E_{\mathrm{E}} \text { of compost }\right) \\
& +W_{2} \times\left(\% E_{\mathrm{E}} \text { of lime }\right)+W_{3} \times\left(\% E_{\mathrm{E}} \text { of } \mathrm{PP}\right) \\
& +W_{4} \times\left(\% E_{\mathrm{E}} \text { for transportation }\right)
\end{aligned}
$$

where $W_{1}=W_{2}=W_{3}=W_{4}=0 \cdot 25$. Table 1 documents the impact on resources including the $I_{\operatorname{Rec}}$ values for the different treatment methods. It can be seen that $8 \%$ lime treatment, with an $I_{\text {Rec }}$ of $16 \cdot 13$, consumes the least resources. This may be attributed to the lower quantity of material used $(7680 \mathrm{~kg}$ of lime against $19200 \mathrm{~kg}$ of compost) and the relatively low embodied energy per unit of material produced $(5.3 \mathrm{MJ} / \mathrm{kg}$ of lime against $115 \mathrm{MJ} / \mathrm{kg}$ of PP fibres). The other treatment methods exhibit similar impacts on resource use $\left(I_{\operatorname{Rec}} \geq 25\right)$.

\subsection{Environmental impact}

The EIA for this study comprises three subindicators. These are global warming potential, acidification potential and eutrophication potential. The stabilisers are not expected to emit chlorofluorocarbons and halons and do not pose a significant risk to the ozone concentration in the stratosphere. The global warming potential $\left(G_{\mathrm{WP}}\right)$ subsumes the impact of climate change and can be described as the increase in the concentration of greenhouse gases that could cause a surge in the average global temperature. In the context of this study, it represents the global warming potential of carbon dioxide measured as kilograms carbon dioxide equivalent $\left(\mathrm{kgCO}_{2} \mathrm{e}\right)$ per kilogram of stabiliser used. The acidification potential $\left(A_{\mathrm{P}}\right)$ refers to the tendency of the additive to increase the acidity (lower the $\mathrm{pH}$ ) of soil and nearby water. It is commonly expressed as grams of sulfur dioxide equivalent $\left(\mathrm{gSO}_{2} \mathrm{e}\right)$. An indicator of biodiversity and ecological health is the eutrophication potential $\left(E_{\mathrm{P}}\right)$, which is a function of biological activity. It has been reported as grams of phosphate equivalent $\left(\mathrm{gPO}_{4}{ }^{3-} \mathrm{e}\right)$. Overnutrification results in excessive biological activity of organisms, which may lead to oxygen deficiency in the environment (Haselbach and Langfitt, 2015). Data for human toxicity potential could not be collected and are excluded from the ambit of this study.

The global warming potential is accorded a higher weight of $0 \cdot 4$ due to its relative importance over the other impact categories.

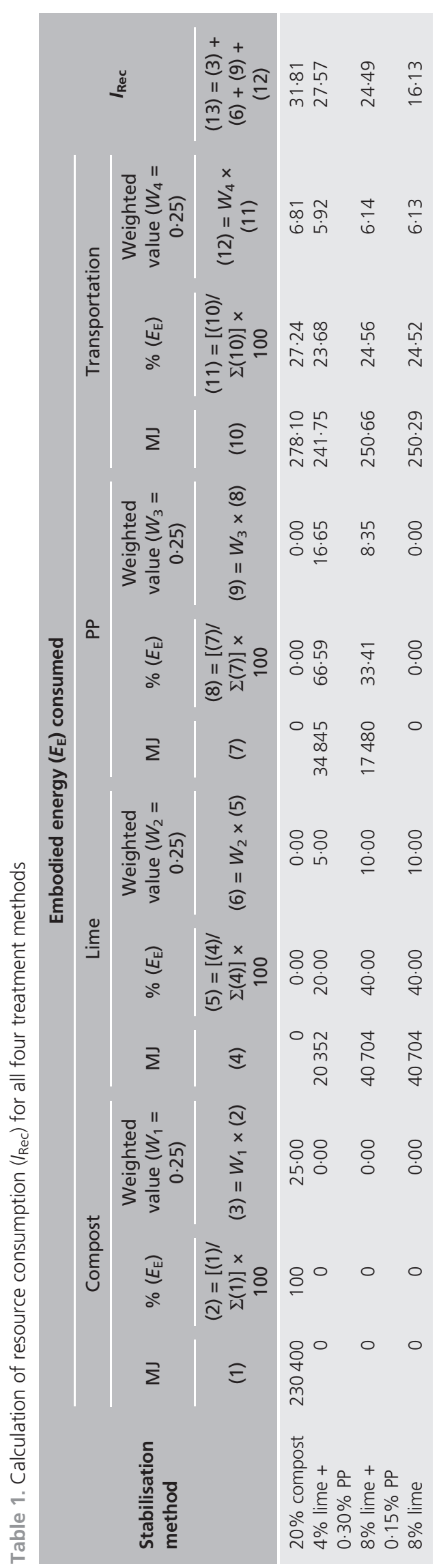


Embodied carbon values for lime and PP were accessed from the ICE database and Aziz et al.'s (2015) report on the carbon dioxide emissions, acidification potential and eutrophication potential of granular compost. Acidification potential and eutrophication potential values for lime and PP were obtained from the studies by Thannimalay et al. (2013) and Yin et al. (2016). Carbon dioxide emissions during the transportation of stabilisers from the manufacturing plant to the dam site have been considered in the analysis. The equation for determining the environmental impact index $\left(I_{\text {Env }}\right)$ can be written as

$$
\begin{aligned}
I_{\mathrm{Env}}= & W_{1} \times\left(\% G_{\mathrm{WP}}\right)+W_{2} \times\left(\% A_{\mathrm{P}}\right) \\
& +W_{3} \times\left(\begin{array}{ll}
\% & E_{\mathrm{P}}
\end{array}\right)
\end{aligned}
$$

where $W_{1}=0 \cdot 4$ and $W_{2}=W_{3}=0 \cdot 3$. Table 2 illustrates the calculation of the three metrics $G_{\mathrm{WP}}, E_{\mathrm{P}}$ and $A_{\mathrm{P}}$ along with the $I_{\text {Env }}$ values for all four surficial slope treatments. The $I_{\text {Env }}$ value for compost treatment is substantially higher due to the high amount $(20 \%)$ of material used in the treatment as well as the high acidification and eutrophication potentials of these materials. Isolated lime and combined lime and fibre treatments exhibited similar $I_{\text {Env }}$ values, which are significantly lower due to the smaller dosages used and the lower $A_{\mathrm{P}}$ and $E_{\mathrm{P}}$ values compared with those for compost treatments.

\subsection{Socio-economic impact}

A significant component of any sustainability framework is the influence it has on the society. A quantifiable attribute of social impact is cost-benefit analysis. The societal benefits are manifold as dams control floods, create reservoirs for water storage, facilitate irrigation and generate electricity, besides providing recreational facilities. Considering that each stabilisation method yields the same benefits, the initial cost of treatment is designated as the sole metric for evaluating financial returns. The costs incurred towards site investigation and consultant fees are assumed to be the same for each treatment method. The operation and maintenance costs have not been factored into the socio-economic impact analysis. It is worthwhile noting that maintenance costs are linked to the resilience of the stabilised system. A robust system would be less susceptible to recurring surficial failures and would incur lower repair costs. The consideration of resilience in the subsequent sections is expected to account for these costs. Community health and well-being are also vital. The noise levels and vibration due to construction machinery and downtime for maintenance and repairs would affect all the stakeholders in the area. This is an unquantifiable metric for this particular study and is similar across all methods. An often-overlooked non-quantifiable facet affecting sustainability is policy constraint. Local policy might dictate consultants and contractors to favour a time-tested practice as opposed to a new treatment method. The equation for socioeconomic impact $\left(I_{\mathrm{SoEc}}\right)$ may be expressed as

3. $I_{\mathrm{SoEc}}=W_{1} \times(\%$ cost $)$

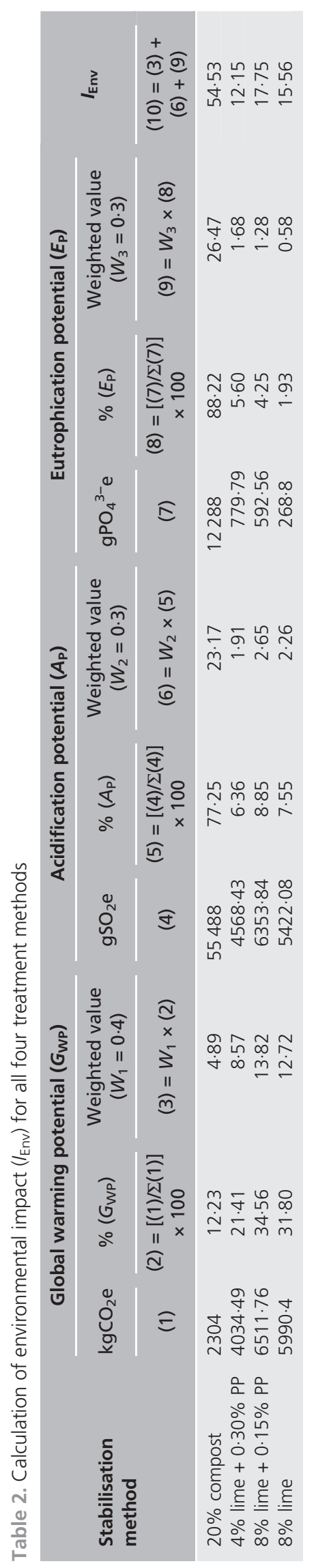


where $W_{1}=1 \cdot 0$. Table 3 shows the quantifiable aspects of socioeconomic impact. The initial cost of treatment is higher for methods where lime and PP fibres are used together. It is interesting to note that the cost incurred for compost treatment is significantly less than the costs of the other methods. If economy solely dictates the selection process, compost would be the recommended alternative, with a low $I_{\mathrm{SoEc}}$ of 5·47.

\subsection{Sustainability index}

As mentioned earlier, sustainability encompasses resource use, environmental impact and socio-economic impact. The sustainability index $\left(I_{\text {Sus }}\right)$ was computed, assigning a higher priority towards environmental impact and socio-economic impact. For this particular case study, it is reckoned that promoting cost effectiveness and minimising the detrimental impact on environment is more exigent over limiting resource consumption. The sustainability index is given by

$$
\begin{aligned}
& I_{\text {Sus }}=W_{1} \times\left(\% I_{\text {Rec }}\right)+W_{2} \times\left(\% I_{\text {Env }}\right) \\
& \text { 4. } \quad+W_{3} \times\left(\% I_{\mathrm{SoEc}}\right)
\end{aligned}
$$

where $W_{1}=0 \cdot 2$ and $W_{2}=W_{3}=0 \cdot 4$. Table 4 describes the $I_{\text {Sus }}$ for all treatment methods. It may be noted that, in this particular study, a lower $I_{\text {Sus }}$ value corresponds to a better sustainable alternative. Accordingly, $8 \%$ lime with an $I_{\text {Sus }}$ of 16.57 is the most sustainable treatment method, whereas compost treatment ranks poorly in sustainability. The environmental impact and resource consumption for compost outweigh its positive socioeconomic impact, leading to a high $I_{\text {Sus }}$ of $30 \cdot 36$. Treatments using a combination of lime and PP fibres have similar sustainability indices.

\subsection{Resilience}

The city resilience index compiled by Arup (da Silva and Morera, 2014) for 'understanding and measuring city resilience' has been extended to analyse the resilience of the stabilised system. Based on the report, the framework identifies four key parameters for evaluating resilience - robustness, reliability, adaptiveness and resourcefulness. The robustness of the system is its capacity to endure hazardous events (intense rainfall, flooding and earthquakes) without significant loss of functionality or structural integrity over time. This attribute reflects the soundness of design of the engineered slope system. The factor of safety $\left(F_{\mathrm{S}}\right)$ against sliding was calculated to gauge the robustness of the treated sections. The strength parameters for slope stability analyses were determined from a rigorous laboratory testing protocol. Two scenarios were conceived for performing stability analyses. The first case assumed the dam slope to have peak strength during a dry summer season. This resulted in a very high factor of safety (more than 10.0) for each treated section, including the control section. The second case considered residual strength parameters assuming all desiccated zones within the dam slope to be saturated during the wet season. This approach is more conservative and was used to determine the factor of safety $\left(F_{\mathrm{S}}\right)$ against shallow failure. Table 5 shows the results of slope stability analyses.

However, an $F_{\mathrm{S}}$-based approach does not account for uncertainties in the determination of strength parameters. The uncertainties could be due to the inherent variability in geotechnical properties and/or the operator dependence of laboratory tests (Ang and Tang, 2007; Baecher and Christian, 2003). Results from reliability analyses performed by Hernandez et al. (2013) for control and treated sections are shown in Figure 8. The analysis is based on a first-order second-moment method developed by Christian et al.

\begin{tabular}{|c|c|c|c|c|}
\hline \multirow{3}{*}{ Stabilisation method } & \multicolumn{3}{|c|}{ Cost of treatment } & \multirow{3}{*}{$\frac{I_{\text {SOEC }}}{(4)=(3)}$} \\
\hline & US\$ & $\%$ (cost) & Weighted value $\left(W_{1}=1 \cdot 0\right)$ & \\
\hline & (1) & $(2)=[(1) / \Sigma(1)] \times 100$ & (3) $=W_{1} \times(2)$ & \\
\hline $20 \%$ compost & 487 & $5 \cdot 47$ & $5 \cdot 47$ & 5.47 \\
\hline $4 \%$ lime $+0.30 \%$ PP & 3510 & $39 \cdot 41$ & $39 \cdot 41$ & $39 \cdot 41$ \\
\hline $8 \%$ lime $+0.15 \%$ PP & 3324 & $37 \cdot 32$ & $37 \cdot 32$ & $37 \cdot 32$ \\
\hline $8 \%$ lime & 1586 & $17 \cdot 81$ & $17 \cdot 81$ & $17 \cdot 81$ \\
\hline
\end{tabular}

Table 3. Calculation of socio-economic impact $\left(I_{\text {SOEc }}\right)$ for all four treatment methods

\begin{tabular}{|c|c|c|c|c|c|c|c|}
\hline \multirow{3}{*}{$\begin{array}{l}\text { Stabilisation } \\
\text { method }\end{array}$} & \multicolumn{2}{|c|}{ Resource consumption } & \multicolumn{2}{|c|}{ Environmental impact } & \multicolumn{2}{|c|}{ Socio-economic impact } & \multirow[b]{2}{*}{$I_{\text {Sus }}$} \\
\hline & $I_{\text {Rec }}$ & $\begin{array}{l}\text { Weighted } I_{\text {Rec }} \\
\left(W_{1}=0.2\right)\end{array}$ & $I_{\text {Env }}$ & $\begin{array}{l}\text { Weighted } I_{\text {Env }} \\
\quad\left(W_{2}=0.4\right)\end{array}$ & $I_{\text {SOEC }}$ & $\begin{array}{l}\text { Weighted } I_{\text {SoEc }} \\
\quad\left(W_{3}=0.4\right)\end{array}$ & \\
\hline & (1) & $(2)=W_{1} \times(1)$ & (3) & $(4)=W_{2} \times(3)$ & (5) & $(6)=W_{3} \times(5)$ & $(7)=(2)+(4)+(6)$ \\
\hline $20 \%$ compost & $31 \cdot 81$ & $6 \cdot 36$ & $54 \cdot 53$ & $21 \cdot 81$ & $5 \cdot 47$ & $2 \cdot 19$ & $30 \cdot 36$ \\
\hline $4 \%$ lime $+0.30 \%$ PP & 27.57 & $5 \cdot 51$ & $12 \cdot 15$ & 4.86 & $39 \cdot 41$ & $15 \cdot 76$ & $26 \cdot 14$ \\
\hline $8 \%$ lime $+0.15 \%$ PP & $24 \cdot 49$ & 4.90 & $17 \cdot 75$ & $7 \cdot 10$ & $37 \cdot 32$ & 14.93 & $26 \cdot 93$ \\
\hline $8 \%$ lime & $16 \cdot 13$ & $3 \cdot 23$ & $15 \cdot 56$ & $6 \cdot 22$ & $17 \cdot 81$ & $7 \cdot 12$ & $16 \cdot 57$ \\
\hline
\end{tabular}

Table 4. Computation of sustainability index (/ sus $\left._{\text {s }}\right)$ 
Engineering Sustainability

Volume 171 Issue ES1
Sustainability and resilience analyses in

slope stabilisation

Das, Puppala, Bheemasetti, Walshire and Corcoran
Table 5. Factor of safety and reliability index for all sections (Hernandez et al., 2013)

\begin{tabular}{|lcc|}
\hline Stabilisation method & Factor of safety & Reliability index \\
\hline Control & 0.82 & -1.32 \\
$20 \%$ compost & 1.37 & 2.76 \\
$4 \%$ lime $+0.30 \%$ PP & 2.65 & 5.40 \\
$8 \%$ lime $+0.15 \%$ PP & 3.55 & 5.75 \\
$8 \%$ lime & 3.04 & 5.73
\end{tabular}

(1994). Bocchini et al. (2013) suggested that resilience should be analysed with a probabilistic perspective. The reliability index and probability of failure could be better indicators of the robustness and overall resilience of the stabilised system.

Adaptiveness refers to the flexibility of the system to adapt in response to perceived disruptions. The rapidity with which such distress can be addressed determines the resourcefulness of the system. Field instrumentation with long-term monitoring can capture the distress in the system with reasonable accuracy. Table 6 reports the maximum lateral movement recorded by inclinometers in the field. Each section was instrumented with two $4.57 \mathrm{~m}$ long and $7 \mathrm{~cm}$ dia. vertical inclinometers, one at the top and the other near the bottom of the slope. The inclinometers were taken to a depth of $4 \mathrm{~m}$ into the ground with a projection of $0.6 \mathrm{~m}$ above the ground surface. The field data, being more accurate and reliable than results from laboratory tests, are assigned a weight of $0 \cdot 6$. The constructability of each stabilisation system being similar, the adaptiveness and resourcefulness is assumed to be the same for each method. In this case, resilience is a function of the maximum lateral movement and probability of failure, denoted by

$$
\text { 5. } \begin{aligned}
I_{\mathrm{Res}}= & W_{1} \times(\% \text { average movement at top and bottom }) \\
& +W_{2} \times\left(\% P_{\mathrm{F}}\right)
\end{aligned}
$$

where $W_{1}=0.6$ and $W_{2}=0.4$. Table 7 demonstrates the parameters that impact resilience. As discussed earlier, a low $I_{\text {Res }}$ value indicates a more resilient alternative. The maximum lateral movement for the $20 \%$ compost-treated section was $27 \mathrm{~mm}$, which is substantially higher than that of the other systems (less than $10 \mathrm{~mm}$ ). Hence, the compost-treated section has the least resilience $\left(I_{\text {Res }}=72\right)$. On the other hand, the $8 \%$ lime-treated section indicates good resilience.

\subsection{Cumulative sustainable and resilience index ( $\left.I_{\mathrm{CSR}}\right)$}

The cumulative sustainable and resilience index $\left(I_{\mathrm{CSR}}\right)$ is a function of the sustainability index and resilience index. It is calculated as shown in Table 8. Resilience would be paramount for the safety and functionality of the dam. Hence, it is accorded the highest weightage of $0 \cdot 6$. The cumulative sustainable and resilience index is expressed as

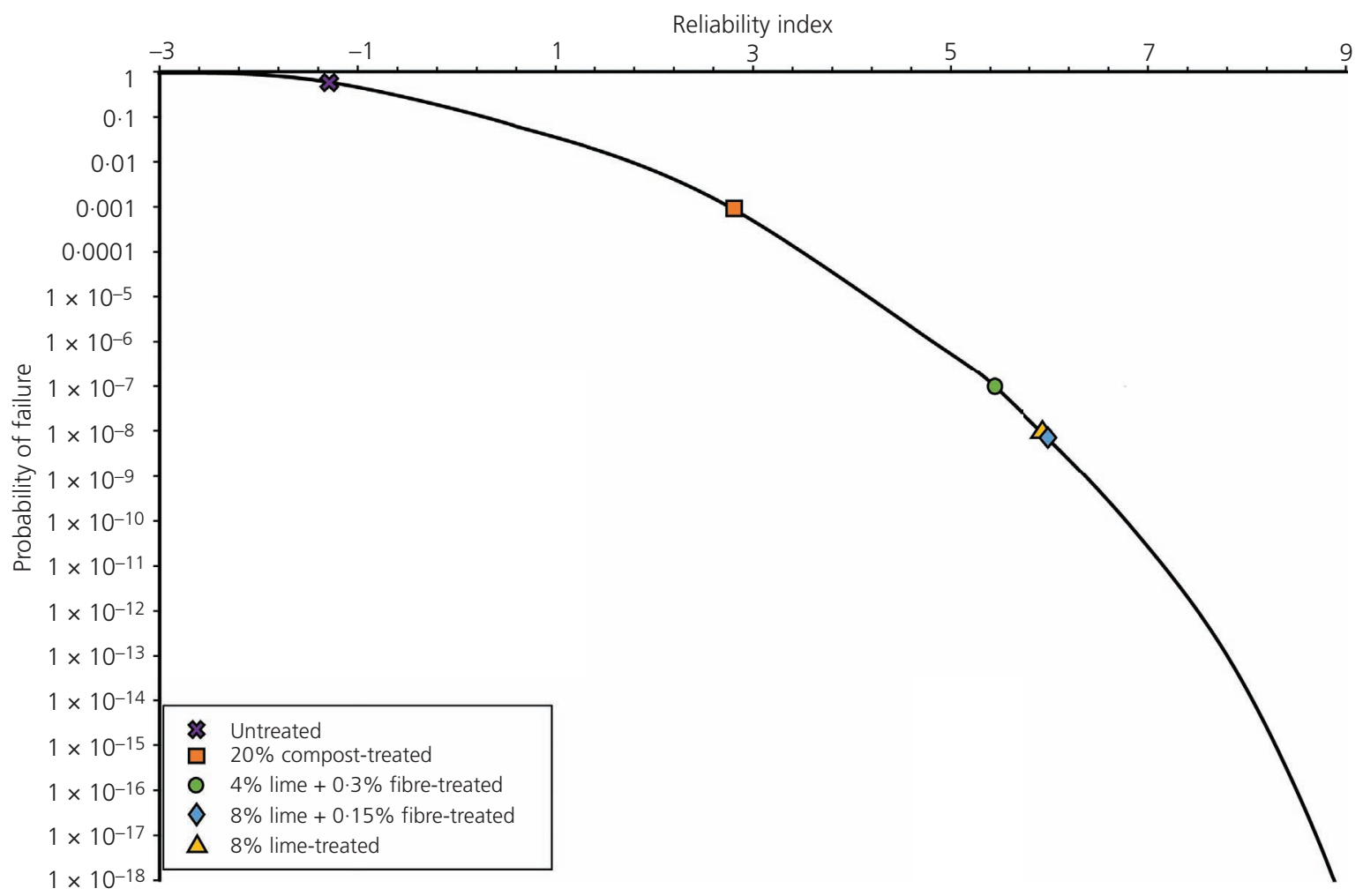

Figure 8. Reliability against probability of failure (after Hernandez et al., 2013) 
Sustainability and resilience analyses in

slope stabilisation

Das, Puppala, Bheemasetti, Walshire and Corcoran
Table 6. Maximum lateral movement $(\mathrm{mm})$ recorded by inclinometers (Le, 2013)

\begin{tabular}{|lrc|}
\hline \multirow{2}{*}{ Stabilisation method } & \multicolumn{2}{c|}{ Inclinometer reading: $\mathbf{~ m m}$} \\
\cline { 2 - 3 } & \multicolumn{1}{c|}{ Top } & Bottom \\
\hline 20\% compost & 24.13 & 30.48 \\
$4 \%$ lime $+0.30 \%$ PP & 8.89 & $10 \cdot 16$ \\
$8 \%$ lime $+0.15 \%$ PP & $7 \cdot 62$ & 8.89 \\
$8 \%$ lime & 5.84 & 6.35 \\
\hline
\end{tabular}

6. $I_{\mathrm{CSR}}=W_{1} \times I_{\mathrm{Sus}}+W_{2} \times I_{\mathrm{Res}}$

where $W_{1}=0 \cdot 4$ and $W_{2}=0 \cdot 6$. Among the four treatment methods, $8 \%$ lime treatment would be the most recommended alternative based on the least cumulative impact index value of 10.92. Treatment with $20 \%$ compost, with a high $I_{\mathrm{CSR}}$ of $55 \cdot 35$, ranks low in terms of both sustainability and resilience. It is also observed that altering the proportion of lime and PP fibres does not have any appreciable effect towards sustainability and resilience. The findings are also presented in the radar chart shown in Figure 9. This indicates that $8 \%$ lime treatment has the least impact across all categories, as it occupies the least area on the chart.

There are certain limitations in the present framework and efforts are being made to address these in future studies. First, nonquantifiable metrics such as noise, vibrations, downtime and policy constraints could not be incorporated into the analysis. Second, the adopted methodology does not illustrate the true interdependence between resilience and sustainability. These two aspects were analysed as separate entities and then combined to yield the $I_{\mathrm{CSR}}$. It is well known that some overlap exists, and future research should be directed towards a combined probabilistic treatment of sustainability and resilience that accurately captures the intersecting attributes.

\section{Concluding remarks}

A comprehensive framework to assess the sustainability and resilience of civil infrastructure has been presented. Various details on how the framework can be used were explained using a slope stabilisation project. The focus was on hardening the surficial slopes of the dams so that they do not undergo recurring surficial slope failures. Several treatment methods were explored for strengthening the dam embankment soils. All these treatments were fully assessed with the proposed framework in terms of enhancing both sustainability and resilience characteristics. The sustainability index ( $\left.I_{\text {Sus }}\right)$ was determined based on resource consumption (embodied energy), environmental impact (global warming potential, acidification potential and eutrophication potential) and socio-economic impact (cost). The resilience index $\left(I_{\text {Res }}\right)$ of the treatments was quantified using the probability of failure $\left(P_{\mathrm{F}}\right)$ and maximum lateral movement observed in the field. The cumulative sustainability and resilience index $\left(I_{\mathrm{CSR}}\right)$ was then introduced to parametrise both these modules together. Based on this combined evaluation, the $8 \%$ lime treatment method, having the least $I_{\mathrm{CSR}}$, was judged to be the most appropriate stabilisation method.

The proposed framework is flexible in the sense that it allows the operator to attach weights to the different sustainability and resilience elements based on his/her discretion. The rationale behind a higher weight being attached to resilience as compared with sustainability in

Table 7. Computation of resilience index ( $\left(I_{\text {Res }}\right)$

\begin{tabular}{|c|c|c|c|c|c|c|c|}
\hline \multirow{3}{*}{$\begin{array}{l}\text { Stabilisation } \\
\text { method }\end{array}$} & \multicolumn{3}{|c|}{ Maximum lateral movement } & \multicolumn{3}{|c|}{ Probability of failure } & \multirow[b]{2}{*}{$I_{\text {Res }}$} \\
\hline & $\mathrm{mm}$ & $\begin{array}{l}\% \text { average } \\
\text { movement }\end{array}$ & $\begin{array}{l}\text { Weighted value } \\
\qquad\left(W_{1}=0.6\right)\end{array}$ & $P_{\mathrm{F}}$ & $\%\left(P_{\mathrm{F}}\right)$ & $\begin{array}{l}\text { Weighted value } \\
\qquad\left(W_{2}=0.4\right)\end{array}$ & \\
\hline & (1) & $\begin{array}{c}(2)=[(1) / \Sigma(1)] \times \\
100\end{array}$ & $(3)=W_{1} \times(2)$ & (4) & $\begin{array}{c}(5)=[(4) / \Sigma(4)] \\
\times 100\end{array}$ & $(6)=W_{2} \times(5)$ & $\begin{array}{c}(7)=(3)+ \\
(6)\end{array}$ \\
\hline $20 \%$ compost & $27 \cdot 31$ & $53 \cdot 34$ & $32 \cdot 00$ & $3.05 \times 10^{-3}$ & $99 \cdot 9988$ & 39.99950 & $72 \cdot 00$ \\
\hline $4 \%$ lime $+0.30 \%$ PP & $9 \cdot 53$ & $18 \cdot 61$ & $11 \cdot 17$ & $2.84 \times 10^{-8}$ & 0.0009 & 0.00037 & $11 \cdot 17$ \\
\hline $8 \%$ lime $+0.15 \% P P$ & $8 \cdot 26$ & $16 \cdot 13$ & 9.68 & $3.62 \times 10^{-9}$ & 0.0001 & 0.00005 & $9 \cdot 68$ \\
\hline $8 \%$ lime & $6 \cdot 10$ & 11.91 & $7 \cdot 15$ & $5.90 \times 10^{-9}$ & 0.0002 & 0.00008 & $7 \cdot 15$ \\
\hline
\end{tabular}

Table 8. Computation of cumulative sustainability and resilience index ( $\left.I_{\text {CSR }}\right)$

\begin{tabular}{|c|c|c|c|c|c|}
\hline \multirow{3}{*}{ Stabilisation method } & \multicolumn{2}{|r|}{ Sustainability } & \multicolumn{2}{|r|}{ Resilience } & \multirow{2}{*}{$I_{\mathrm{CSR}}$} \\
\hline & Isus & Weighted $I_{\text {sus }}\left(W_{1}=0.4\right)$ & $I_{\text {Res }}$ & Weighted $I_{\text {Res }}\left(W_{2}=0.6\right)$ & \\
\hline & (1) & $(2)=W_{1} \times(1)$ & (3) & $(4)=W_{2} \times(3)$ & $(5)=(2)+(4)$ \\
\hline $20 \%$ compost & $30 \cdot 36$ & $12 \cdot 14$ & $72 \cdot 00$ & $43 \cdot 20$ & $55 \cdot 35$ \\
\hline $4 \%$ lime $+0.30 \% \mathrm{PP}$ & $26 \cdot 14$ & $10 \cdot 46$ & $11 \cdot 17$ & $6 \cdot 70$ & $17 \cdot 16$ \\
\hline $8 \%$ lime $+0.15 \% \mathrm{PP}$ & $26 \cdot 93$ & $10 \cdot 77$ & $9 \cdot 68$ & $5 \cdot 81$ & $16 \cdot 58$ \\
\hline $8 \%$ lime & $16 \cdot 57$ & $6 \cdot 63$ & $7 \cdot 15$ & $4 \cdot 29$ & $10 \cdot 92$ \\
\hline
\end{tabular}


Engineering Sustainability

Volume 171 Issue ES1
Sustainability and resilience analyses in

slope stabilisation

Das, Puppala, Bheemasetti, Walshire and Corcoran

- $20 \%$ compost $\quad--4 \%$ lime $+0.30 \%$ fibres $\ldots . .8 \%$ lime $+0.15 \%$ fibres $\quad-8 \%$ lime

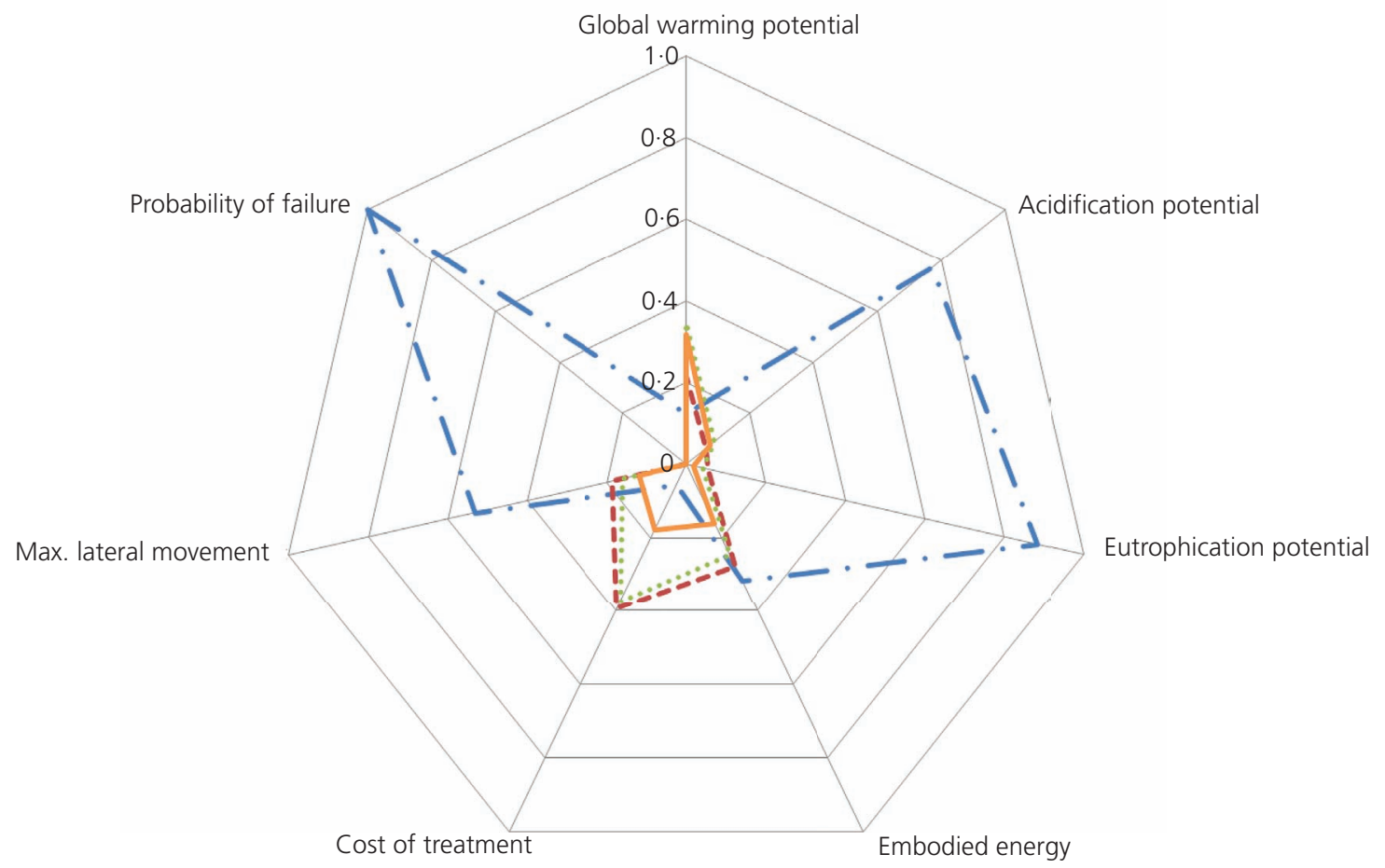

Figure 9. Radar chart depicting all impact categories (internally normalised)

the present example is that surficial slope failures, being a recurring phenomenon during both dry and wet seasons in Texas, involve high annual repair costs. Furthermore, the propensity of geoprofessionals towards higher resilience in design might lead to a lesser weight being assigned to sustainability elements.

\section{Acknowledgements}

The test section described in this paper came from a recently completed research project funded by the USACE, Fort Worth District. The authors would like to acknowledge the partial grant support provided by the National Science Foundation Industry-University Cooperative Research Centers Program, Award 1464489 (PD: Dr Raffaella Montelli). The authors would also like to acknowledge Ashraf Sarwenaj, Kenneth L. McCleskey, Jason Vazquez, Mark Black, Les Perrin, Jose Hernandez and former UTA doctoral students Venkat Dronamraju, Minh Le and Raju Acharya for the support provided in both the laboratory and field research activities of this project.

\section{REFERENCES}

Abramson WL, Lee ST, Sharma S and Boyce MG (2002) Slope Stability and Stabilization Methods, 2nd edn. Wiley, New York, NY, USA.

Abreu DG, Jefferson I, Braithwaite PA and Chapman DN (2008) Why is sustainability important in geotechnical engineering? In GeoCongress 2008: Geosustainability and Geohazard Mitigation (Reddy KRR, Khire MV and Alshawabkeh AN (eds)). American Society of Civil Engineers, Reston, VA, USA, pp. 821-828.
Ang AHS and Tang WH (2007) Probabilistic Concepts in Engineering: Emphasis on Applications to Civil and Environmental Engineering, 2nd edn. John Wiley \& Sons, Inc., Hoboken, NJ, USA.

Aziz R, Chevakidagarn P and Danteravanich S (2015) Environmental impact evaluation of community composting by using life cycle assessment: a case study based on types of compost product operations. Walailak Journal of Science and Technology (WJST) 13(3) 221-233, http://dx.doi.org/10.14456/WJST.2016.21.

Baecher GB and Christian JT (2003) Reliability and Statistics in Geotechnical Engineering. John Wiley \& Sons Inc., New York, NY, USA.

Basu D, Misra A and Puppala AJ (2014) Sustainability and geotechnical engineering: perspectives and review. Canadian Geotechnical Journal 52(1): 96-113, http://dx.doi.org/10.1139/cgj-2013-0120.

Bocchini P, Frangopol DM, Ummenhofer T and Zinke T (2013) Resilience and sustainability of civil infrastructure: toward a unified approach. Journal of Infrastructure Systems 20(2): 04014004, http://dx.doi.org/ 10.1061/(ASCE)IS.1943-555X.0000177.

Bruneau M, Chang S, Eguchi R et al. (2003) A framework to quantitatively assess and enhance the seismic resilience of communities. Earthquake Spectra 19(4): 733-752, http://dx.doi.org/ 10.1193/1.1623497.

Chau C, Soga K and Nicholson D (2006) Comparison of embodied energy of four different retaining wall systems. In Proceedings of International Conference on Reuse of Foundations for Urban Sites (Butcher AP, Powell JJM and Skinner HD (eds)). IHS BRE Press, Bracknell, UK, pp. 277-286.

Christian JT, Ladd CC and Baecher GB (1994) Reliability applied to slope stability analysis. ASCE Journal of Geotechnical Engineering 120(12) 2180-2207, http://dx.doi.org/10.1061/(ASCE)0733-9410(1994)120:12 (2180). 
Engineering Sustainability

Volume 171 Issue ES1
Sustainability and resilience analyses in

slope stabilisation

Das, Puppala, Bheemasetti, Walshire and Corcoran da Silva J and Morera BE (2014) City Resilience Index. The Rockefeller Foundation and Arup, London, UK. See http://www.arup.com/cri (accessed 08/12/2016)

Day RW and Axten GW (1989) Surficial stability of compacted clay slopes. Journal of Geotechnical Engineering 115(4): 577-580.

Dronamraju VS (2008) Studies on Field Stabilization Methods to Prevent Surficial Slope Failures of Earthfill Dams. PhD thesis, University of Texas at Arlington, Arlington, TX, USA.

Evans DA (1972) Slope Stability Report. Slope Stability Committee, Department of Building and Safety, Los Angeles, CA, USA

Finnveden G (1999) A Critical Review of Operational Valuation/ Weighting Methods for Life Cycle Assessment. AFN (Swedish Waste Research Council), Naturvårdsverket, Stockholm, Sweden.

Hammond G, Jones C, Lowrie F and Tse P (2011) Embodied Carbon - the Inventory of Carbon and Energy (ICE). University of Bath and BSRIA, Bracknell, UK.

Haselbach L and Langfitt Q (2015) Transportation Life Cycle Assessment (LCA) Synthesis: Life Cycle Assessment Learning Module Series. US Department of Transportation, Center for Environmentally Sustainable Transportation in Cold Climates and University of Alaska Fairbanks, Fairbanks, AK, USA.

Hernandez J, Chittoori BC, Le M et al. (2013) Economical and reliable solutions for arresting surficial slope failures in earthen dams. 33rd Annual USSD Conference, 11-15 February, Phoenix, AZ, USA, pp. 1345-1358.

Holt DGA, Jefferson I, Braithwaite PA and Chapman DN (2009) Embedding sustainability into geotechnics. Part A: methodology. Proceedings of the Institution of Civil Engineers - Engineering Sustainability 163(3): 127-135, http://dx.doi.org/10.1680/ensu.2010. 163.3.127.

IUCN, UNEP and WWF (International Union for Conservation of Nature, UN Environment Programme and World Wildlife Fund) (1991) Caring for Earth: a Strategy for Sustainable Living. IUCN, UNEP and WWF, Gland, Switzerland.

Jefferis SA (2008) Moving towards sustainability in geotechnical engineering. In GeoCongress 2008: Geosustainability and Geohazard Mitigation (Reddy KRR, Khire MV and Alshawabkeh AN (eds)). American Society of Civil Engineers, Reston, VA, USA, pp. 844-851.

Jimenez M (2004) Assessment of Geotechnical Process on the Basis of Sustainability Principles. MSc thesis, University of Birmingham, Birmingham, UK.

Le M (2013) Investigations to Develop Field Stabilization Methods to Mitigate Surficial Slope Failures. PhD thesis, University of Texas at Arlington, Arlington, TX, USA.

Long JCS, Amadei B, Bardet JP et al. (2006) Geological and Geotechnical Engineering in the New Millennium: Opportunities for Research and Technological Innovation: Opportunities for Research and Technological Innovation. National Academies Press, Washington, DC, USA.

McCleskey LK Jr (2005) Experimental Investigations to Select Stabilization Methods to Mitigate Embankment Desiccation Cracks in order to Reduce Slope Failures. MS thesis, University of Texas at Arlington, Arlington, TX, USA.

Misra A (2010) A Multicriteria Based Quantitative Framework for Assessing the Sustainability of Pile Foundations. MS thesis, University of Connecticut, Storrs, CT, USA.

NCHRP (National Cooperative Highway Research Program) (2012) Costeffective and Sustainable Road Slope Stabilization and Erosion Control. NCHRP, Transportation Research Board, Washington, DC, USA.

Pantelidou H, Nicholson D and Gaba A (2012) Sustainable geotechnics. In Manual of Geotechnical Engineering (Burland J, Chapman T, Skinner $\mathrm{H}$ and Brown M (eds)). ICE Publishing, London, UK, vol. 1, pp. $125-135$.

Pender MJ (2011) Prologue: Designing for sustainability from the big picture to the geotechnical contribution. In Geotechnics and
Earthquake Geotechnics towards Global Sustainability (Iai S (ed.)). Springer, Dordrecht, the Netherlands, pp. vii-xiii.

Puppala JA and Musenda C (2000) Effects of fiber reinforcement on strength and volume change behavior of expansive soils. Proceedings of the 79th Annual Meeting of the Transportation Research Board, 9-13 January, Washington, DC, USA, pp. 134-140

Puppala AJ, Banavathu N, Qasim SR, Williammee R and Intharasombat N (2005) Laboratory investigations to address the use of compost amendments to enhance expansive subsoils. In Recycled Materials in Geotechnics (Aydilek AH and Wartman J (eds)). American Society of Civil Engineers, Reston, VA, USA, Geotechnical Special Publication 127, pp. 91-104

Puppala AJ, Chittoori BC, Talluri N et al. (2013) Stabilizer selection for arresting surficial slope failures: a sustainability perspective. In Geocongress 2013: Stability and Performance of Slopes and Embankments III (Meehan C, Pradel D, Pando MA and Labuz JF (eds)). American Society of Civil Engineers, Reston, VA, USA, pp. 1465-1474.

Saride S, Dronamraju V, Puppala AJ et al. (2010) Assessment of stabilization methods to control surficial Slope failures. Transportation Research Board 89th Annual Meeting, Washington, DC, USA, Paper No. 10-2491.

Storesund R, Messe J and Kim Y (2008) Life cycle impacts for concrete retaining walls vs. bioengineered slopes. In GeoCongress 2008 . Geosustainability and Geohazard Mitigation (Reddy KRR, Khire MV and Alshawabkeh AN (eds)). American Society of Civil Engineers, Reston, VA, USA, pp. 875-882.

Thannimalay L, Yusoff S and Zawawi NZ (2013) Life cycle assessment of sodium hydroxide. Australian Journal of Basic and Applied Sciences 7(2): 421-431.

UN General Assembly (2005) World Summit Outcome, Resolution A/60/1, Adopted by the General Assembly on 15 September 2005. UN General Assembly, New York, NY, USA. See http://www.ifrc.org/docs/idrl/ I520EN.pdf (accessed 17/02/2009).

Vinod JS, Indraratna B and Mahamud MAA (2010) Stabilisation of an erodible soil using a chemical admixture. Proceedings of the Institution of Civil Engineers - Ground Improvement 163(1): 43-51, http://dx.doi.org/10.1680/grim.2010.163.1.43.

Wu TH, Trenner BR, Fox PJ et al. (2008) Soil-bioengineering for slope stabilization in Ohio. In GeoCongress 2008: Geosustainability and Geohazard Mitigation (Reddy KRR, Khire MV and Alshawabkeh AN (eds)). American Society of Civil Engineers, Reston, VA, USA, pp. 883-890.

Yin S, Tuladhar R, Sheehan M, Combe M and Collister T (2016) A life cycle assessment of recycled polypropylene fibre in concrete footpaths. Journal of Cleaner Production 112: 2231-2242, http://dx. doi.org/10.1016/j.jclepro.2015.09.073.

\section{How can you contribute?}

To discuss this paper, please email up to 500 words to the editor at journals@ice.org.uk. Your contribution will be forwarded to the author(s) for a reply and, if considered appropriate by the editorial board, it will be published as discussion in a future issue of the journal.

Proceedings journals rely entirely on contributions from the civil engineering profession (and allied disciplines). Information about how to submit your paper online is available at www.icevirtuallibrary.com/page/authors, where you will also find detailed author guidelines. 